\title{
Research on Current Situation and Tendency of the Development of Green Electric Wire and Cable Materials
}

\author{
Su Dandan \\ Wuxi Institute of Arts and Technology, Wuxi, Jiangsu, China \\ Sudandan001@163.com
}

Keywords: Green electric wire and cable materials; Current situation and tendency

\begin{abstract}
Along with the people environmental protection consciousness enhancement, the enterprise and the family are inclined to use the green electric wire and cable to reduce the environmental pollution. This paper firstly introduces the concept of green electric wire and cable, and then expounds thecurrent situation of green electric wire and cable materials, finally gives the development tendency of green electric wire and cable materialsin order to provide references for the related researchers.
\end{abstract}

\section{Concept of Green Electric Wire and Cable}

The green electric wire and cable is also called environmental-friendly electric wire and cable, which is a new type of the wire and cable aggressively promoted in the world. It is characterized little environmental pollution and harm to human body in the product manufacturing and use. The main requirements of green environmental protection cable are no halogen, flame retardant, not produce toxic and corrosive gas, and not contain heavy metals, easy recycling. The main technical conditions for environmental protection type of wire and cable: Cable halogen containing heavy metals and harmful chemicals can cause the air, water and soil pollution, already is an indisputable fact. Europe and Japan and other countries as well as the green peace organization, not only pay attention to the public environment pollution cable products, but also begin to pay close attention to the harm to the ecological environment of the cable factory. Although the name is the instructions of electronic and electrical products sales to the EU countries, but its influence has extended to the whole world.

China's economy has a sustained and rapid development during the thirty years of reform and opening up. Electric wire and cable industry as a kind of important industrial products is closely linked with the national economy. Currently, the capital, technology and personnel and other factors of production have been accumulated, and create good conditionsthrough a large number of technology introduction, digestion and absorption as well as independent research and development.China's wire and cable industry has initially formed a variety of manufacturing capacity, and in the field of low-end products has formed a relatively complete supporting system. With the development of modern science and technology and the improvement of people's living standard, the higher of wire and cable products safety and environmental protection requirements. In 1990s, the development of modification technology and application technology of domestic synthetic resin polymer materials and their blends, promoted the wire and cable industry entered a new era of application materials, especially the low smoke halogen-free flame retardant materials and technology has been widely applied. Cable material is an important factor to determine the performance of the cable, but also one of the focuses of development area.

\section{Current Situation of Green Electric Wire and Cable Materials}

The environmental protection has become the development trend of cable materials industry to cope with the increasingly serious pollution during the use of waste electrical wire and cable. The traditional PVC cable materials not only contain halogen, but also contain heavy metals. The cable material factory and cable factory made a lot of research on green PVC cable material, environmental protection type cable material in China has been commercialized, can fully meet the 
two EU directive requirements. Harmful substances in environmental protection type PVC does not contain the provisions of the EU directive two, but it will be in the combustion produces large amounts of dioxins, HCL and smoke, once the fire happens, it may cause casualties. With the decrease of environmental protection cable material production technology and production cost, power supply departments and users began to gradually accept the environmental protection type of cable materials, especially for the public places of entertainment, hospital, gymnasium, high-rise commercial buildings, hotels and more than 24 layers of commercial residential building mixed with power cables, more and more users to take the initiative to adopt environment-friendly. Therefore, environmental protection of cable materials with low smoke halogen-free flame retardant performance will gradually replace the traditional PVC cable material. At present, PVC cable materials are continuing to enhance the low smoke halogen-free flame retardant polyolefin cable material and cross-linked polyethylene cable material market.

Research on China's low smoke halogen-free flame retardant cable material of thermoplastic began in late twentieth century. With the continuous development of in-depth research and a variety of raw and auxiliary materials, thermoplastic low smoke halogen-free flame retardant cable material in wire and cable industry of our country has play a decisive role. The performance of the product is good, good processing technology of cable, the price cheaper than similar foreign products. The product has strong applicability, wide application rangeand large market demand. Cross-linked polyethylene cable material of halogen free cable material, has the feature of green environmental protection. With the production of cross-linked polyethylene cable material of cross-linked polyethylene insulated power cable not only has good electrical properties, but also has good mechanical properties thermal overload, long-term use of working temperature of $90^{\circ} \mathrm{C}$, short circuit of a high temperature of $250^{\circ} \mathrm{C}$, the same load flow, conductor cross section can be reduced to two, can save $20 \sim 30 \%$ conductor. XLPE cable has the advantages of simple structure, less production procedure, production speed, light weight, low cost, cable installation is simple, the working temperature, mechanical strength, resistance to environmental stress cracking is better than that of PVC cable. In addition, the cross-linked polyethylene cable material has excellent dielectric properties.It is not only used in low voltage, medium voltage power cables, but also widely used in high voltage and high voltage power cable.

The developed countries have always attached great importance to the promotion and application of environmentally friendly productsfor more than 20 years. Electric wire and cable industry is the development and promotion of the use of importance of low smoke halogen free flame retardant cable and related materials. Especially for the important buildings and facilities on the relatively closed or personnel (high-rise buildings, subway, station, airport, station and shopping malls) of fire disaster reduction achieved good results. At present, the developed countries of the low smoke halogen-free flame retardant cable material has formed a relatively complete series, including thermoplastic, chemical crosslinking, radiation crosslinking and saline crosslinking. Thermoplastic is mainly used as the sheath communication cable and power cable, control cable; and crosslinking is mainly used as insulation in certain occasions, such as automotive wire, locomotive vehicle cable, and control cable for ship. In recent years, the developed countries are striving to promote the concept of green environmental protection in electrical and electronic equipment. For example, the Japanese electronics giants (Sony Panasonic, etc.), have made the green plan of their own to prohibit or restrict the use of harmful to human body and environment of heavy metal and halogen. In view of these situations, the main wire and cable manufacturers in Japan have done a lot of research work and successfullylaunched a series of green electric wire and cable.

\section{Tendency of Green Electric Wire and Cable Materials}

Broad Future Prospects.The environmental quality requirements of Chinese are getting higher. The environmental protection has been highlighted as an important livelihood issues. Intensive introduction of the national environmental policy, the environmental battle has begun. Conventional cable in the manufacture, use, and waste treatment process will produce a large amount of dioxins, 
lead, cadmium, halide and other pollution substance, which is bad for the environment. Environmental protection cable has on people and the environment, no pollution, non-toxic, high safety and reliability, long service life, easy recycling economy mode characteristics of separation and recovery. More and more enterprises only continue to try and innovation practice in green products and business, the wire and cable industry in order to achieve sustainable development, showing a vigorous development trend of green.

At present, the green environmental protection type cable of domestic and foreign representative, such as main flame retardant cable and fireproof cable have higher added value and profits are higher. Therefore, research and development, production and environmental protection cable is likely to make the enterprise from the market of low-end products to high-end products in the market, the efficiency of enterprises will be increased. All countries in the world with the continuous improvement of environmental protection requirements, the international environmental laws and regulations are also increasing. In order to obtain export opportunities abroad, declining production of conventional cable, the cable replace sb. is the production of environmental protection. The domestic wire and cable enterprises must realize the production process of green managements to realize green manufacturing.

Perfect Standard System.Currently, the standard of communication cable and control cable power cable of green materials in China is chaotic. The unified national standard has not yet formed. There are some defects in the industry standard has been promulgated, domestic research, failed to green fuel sheath material production and use have very good specification and guide. Many cable manufacturer of green fuel procurement specification jacket materials are act as one pleases, or performance requirements are too high, or the performance is not balanced, or is missing an important performance requirements, most of the time we focus on the material surface are mainly concentrated in the extrusion, mechanical properties and flame retardant properties, and some of the other an important property is not given enough attention, resulting in the low smoke halogen-free flame retardant sheath material supply market confusion. The communication cable and power cable, control cable low smoke halogen-free flame retardant insulation and sheath, the developed countries has accumulated valuable experience of the development and use, has formed a relatively mature and perfect the standard system of our country should be as close as possible, or equivalent using the international advanced standard, only in this way can we effectively specification of domestic green wire and cable market, promote the progress of science and technology of the wire and cable industry, and guide the healthy development of the wire and cable industry. Electronic electrical wire and cable, the major domestic manufacturers generally use the standard to organize production. The standard is of domestic materials and wire and cable manufacturers should pay close attention to the latest developments in this area.

Advanced Production Processes. As the low smoke halogen-free flame retardant cable material is a composite system of high filling, it is important to obtain good performance of the material to solve the basic resin. The developed countries over the years have been in the development and application of composite coupling technique, while the domestic is relatively lagging behind, need to strengthen. For the vast majority of manufacturers of thermoplastic material is heat-resistant deformation problems, need to work in the aspects of basic resin and filler selection in order to obtain the solution. In the aspect of improving the flame, especially for electric cable, in the use of aluminum hydroxide, magnesium hydroxide and consideration should be given to the development and use of fire retardant synergistic agent, which Japanese major cable manufacturers in the forefront of the domestic demand, and actively carry out the work. In addition, the cross-linked material in domestic chemical crosslinking and material also belongs to the blank in the United States, the former and the latter in the large amount of Europe has started to use a large number, it should carry out the work, is worth considering. It should also be pointed out that low smoke halogen-free flame retardant cable material of the production equipment configuration, performance and process control requirements are higher. The equipment manufacturers should actively attract domestic and foreign experience and constantly improve the level of design and manufacturing. 
Almost no Environmental Pollution.Materials containing Phosphorus is not strict green environmental protection materials, because phosphorus flame retardant materials may cause smoke density and toxicity index exceed the standard. At the same time, flame retardant cable material and leak out of harm to the environment. Therefore, the domestic related materials and wire and cable manufacturers should take measures to stop the production and use of phosphorus containing materials, as soon as possible. The raw material is estimated at present, low smoke non halogen flame retardant cable material manufacturers use about $80 \%$ more are using imported raw materials, which are mainly determined by the domestic resin and inorganic flame retardant industry status. On the basis of domestic resin production, it is suitable for the manufacture of low smoke halogen free flame retardant cable material varieties. While the domestic production of the inorganic flame retardant magnesium hydroxide, aluminum hydroxide minerals mainly adopt mechanical crushing method rather than chemical synthesis method is not suitable for the extensive use of low smoke halogen free flame retardant cable materials. The green wire and cable materials in the future should be non-toxic or low toxic to protect environment.

\section{References}

[1] G.J. Wang,Y.Y. Ma, Analysis and Forecast of Electric Wire and Cable Market, J.Nonferrous Metals Processing. 4(2008) 22-25.

[2] X.R. Chen, Research in the Formulation of a Mouseproof and Environmental Friendly PVC Cable Material, J. Biotechnology Journal. 5(2012) 27- 31.

[3] G.Q. Zhang, W.X. Chen, Q. Lin. Development of SD environmental protection type power cable plastic protection tube, J. Shanghai Electric Power. 3(2006) 34- 36. 